Article

\title{
Design and Numerical Analysis of Mixed Compression Inlet of a Shcramjet Engine
}

\author{
Nitish Acharya *, Sajan Sharma, Lokesh Silwal, and Sudip Bhattrai \\ Department of Mechanical Engineering, Institute of Engineering, Tribhuvan University, P.O.Box 8212, Kirtipur, \\ Kathmandu, Nepal; thesajansharma@gmail.com (S. S.); lokusilwal@gmail.com (L. S.); sudip@ioe.edu.np (S.B.) \\ * Correspondence: nitishacharya1818@gmail.com ; Tel.: +977-9840098100
}

\begin{abstract}
The aim of this work is to present a design approach of a Shock-Induced Combustion Ramjet (Shcramjet) inlet, and present its optimization in terms of the flow and geometrical parameters. The flow properties of mixed compression type inlet of a Shcramjet are examined using analytical and numerical techniques. The geometries obtained with variations in the wedge angles, length, height and cowl lip positions are used to study the flow characteristics of inlet, identifying bow shock temperature ratio as the optimization parameter. The two-dimensional geometries of two-shock and three-shock inlet models designed analytically for shock-on-lip condition at Mach 12.5 and an altitude of $32.5 \mathrm{~km}$ are numerically simulated in OpenFOAM CFD Toolbox. A density based compressible CFD solver based on central upwind schemes of Kurganov and Tadmore is used to solve 2D inviscid Euler equations. The inlet total pressure recovery is expressed as a function of temperature ratios of compression shocks, and is found to have a maxima at a bow shock temperature ratio at the design condition when the bow and external shocks have equal strengths. The effect of considering the flow to be calorically imperfect is studied numerically, and the deviation from the analytical design is presented.
\end{abstract}

Keywords: oblique detonation wave; mixed compression inlet; inlet diffusion; total pressure recovery

\section{Introduction}

Shock-Induced Combustion Ramjet (Shcramjet) [1, 3, 4] engine is a hypersonic air-breathing propulsion system that utilizes induction through shock waves to achieve reactive combustion in a fuel-air mixture flow. In contrast to the slower, diffusive mode of combustion in a Scramjet, ignition in Shcramjet is initiated by shock waves, with a sudden jump in temperature and pressure, allowing combustion to take place at much faster rates. The igniting oblique shock waves (OSWs) can be stabilized over a strut, wedge or ramp in the combustion chamber, hence called 'standing OSWs'. In particular, instead of multiple OSWs, if a single strong OSW is used to ignite the mixture flow at once, the oblique shock and combustion waves form a closely coupled combustion structure called an oblique detonation wave (ODW).

Shcramjet has two important benefits- significantly shorter combustion chamber length and lesser inlet diffusion [2]. The entire Shcramjet vehicle forebody is used as the inlet for compression. The main engine (an elongated channel) on the ventral side of the vehicle consists of injector and combustor, and the entire afterbody is used as the nozzle for flow expansion and generation of thrust. Compared to Scramjet, Shcramjet required lesser inlet diffusion. Hence, it is seen to have superior performance than Scramjet above Mach 12 [3, 4], which can make it a candidate for next stage of propulsion system for hypersonic flight as well as SSTO after Scramjet, or as an alternative to chemical rockets for atmospheric flights up to Mach 22 [2].

The performance of a shock-induced combustion ramjet powered hypersonic vehicle is critically determined by its inlet efficiency [5]. Unlike Scramjet, because of its ability to achieve combustion at higher 
Mach numbers, the compression required at the Shcramjet inlet is not limited by the combustor entrance speed but instead mainly by the entrance temperature, such that no premature ignition of fuel occurs during mixing. Thus, by maintaining the combustor entrance temperature below the auto-ignition temperature, a higher Mach number can result in much effective combustion through an ODW, while at the same time lesser inlet diffusion requiring smaller size of the inlet geometry. Thus, a proper choice of geometric parameters for the inlet will possess a significant impact in overall length and weight of the vehicle.

A mixed compression inlet is characterized by multiple oblique shocks in the hypersonic inlet, generated in the external flow field by the external compression surfaces like ramps, and in the internal flow field from the cowl lip to the combustor face. Smart et al. [6] conducted a study on optimization of two-dimensional Scramjet inlets to explore the performance of mixed compression type inlet operating between Mach 4 and 10 . The study indicated that Scramjet inlets with maximum total pressure recovery have external shocks with almost equal strength. Numerical investigation performed in [7] simulated the inlet experimentally studied by Anderson et al. [8] at design Mach number 3.0 and pressure ratio 31.5. However, at Mach 3, the inlet flow seemed choked. Thus, it was found necessary for the original inlet configuration to either overspeed the flow to Mach 3.05 or increase of the throat area by a minimum of $2 \%$ to start the inlet. This resulted in a total pressure recovery of 0.878 . Haberle et al. in $[9,10]$ studied the effect of bleed dimensions and internal contraction ratios on starting characteristics of two-dimensional and three-dimensional scramjet inlets at high supersonic Mach numbers. The experimental and numerical investigations of mixed compression inlet flow field presented in [11] with different cowl deflections at flight Mach number 2.2 showed that a small angle at cowl lip led to an improvement performance with much efficient start of the flow at intake. Lind et al. [12] studied the interaction of the inlet forebody shock and internal shock at cowl lip to predict the flow stability in the intake. A very high pressure and temperature region around the cowl lip resulted in high instability of flow at entrance.

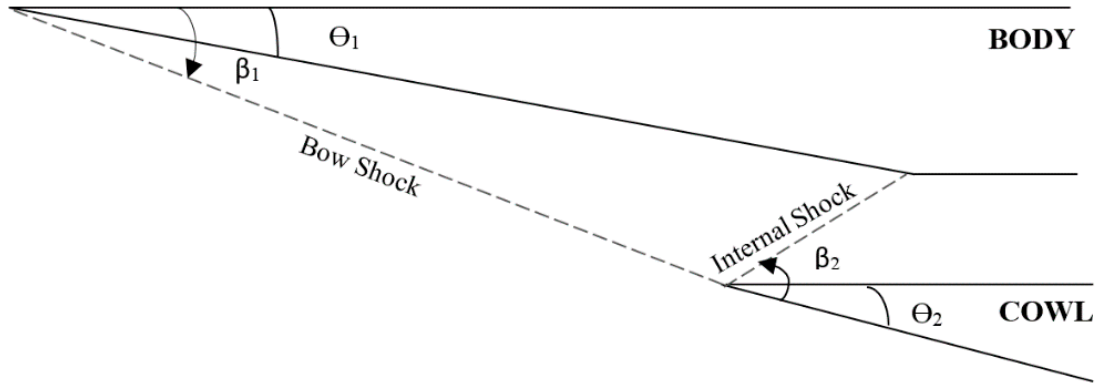

Figure 1. Schematic of two-shock inlet model

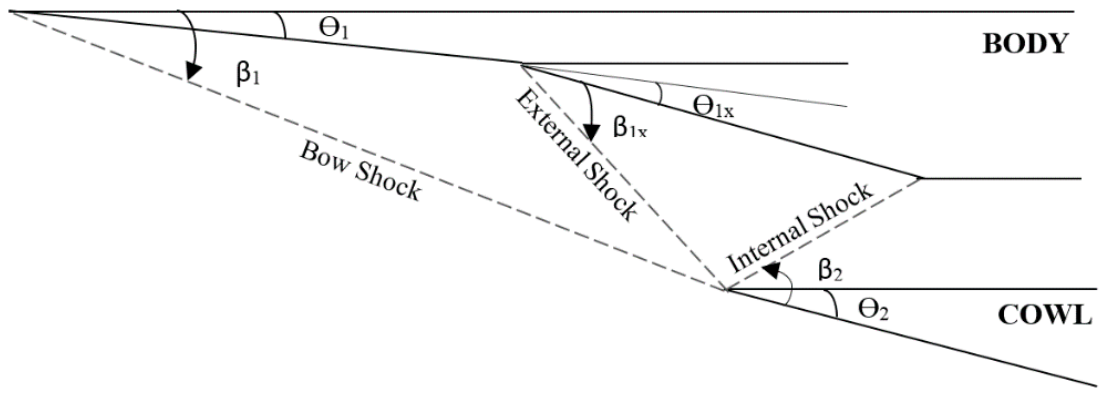

Figure 2. Schematic of three-shock inlet model 
Earliest work in the area of hypersonic air-breathing engines was that of Dunlap et al [13] and Sargeant and Gross [14]. Since then, the field has come across a series of researches in past few decades. Estimation of vehicle sizing and performance were made in [15] using an engineering hypersonic vehicle synthesis code. A method of preliminary design for a two-dimensional, mixed compression, two-ramp supersonic inlet was proposed in [16] to maximize total pressure recovery and match the mass flow demand of the engine. Also, for an off-design condition, an estimation study was performed to calculate the total pressure recovery so that performance of the engine at the off-design condition could be estimated. In [17], a three-dimensional numerical simulation of the aero propulsive performance characteristics of a Scramjet and a Shcramjet at a flight Mach number of 11 was performed. Another comparison study was performed in [3] where the fuelspecific impulse of scramjet given by Heiser and Pratt [18] was compared to that of a Shcramjet. The study took fuel-specific impulse as a function of the flight Mach number. In [19], numerical simulations were performed to study the performance of a streamline traced Busemann inlet $[20,21]$ for hypersonic airbreathing vehicles.

The present paper reports the results of two-dimensional numerical simulation of mixed compression inlets of a Shcramjet. Different inlet geometries are generated analytically using inviscid OSW theory and the respective flow fields are simulated in order to determine the optimum distribution of strengths of the bow, internal and external shocks of a three-shock inlet in terms of temperature ratio, and their performance is compared in terms of the inlet total pressure recovery.

\section{Analytical Design}

The analytical design is performed to match the temperature ratios necessary to achieve desired form of combustion in the combustion channel. Since combustion is through an ODW, the combustion inflow temperature is limited by the auto-ignition temperature for the hydrogen-air mixture in the combustor. For the exit flow to be parallel to the entrance of combustor, a design constraint is satisfied such that the relation between wedge angles, as shown in Figure 1 and Figure 2, is given by:

- $\theta_{1}=\theta_{2}$ (two-shock model)

- $\theta_{1}+\theta_{1 x}=\theta_{2}$ (three-shock model)

The OSWs are assumed to intersect at cowl lip. The combustor (exit of inlet) height of $0.1 \mathrm{~m}$ is used in the study.

Table 1. Shcramjet inlet operating conditions

\begin{tabular}{cc}
\hline Parameters & Value \\
\hline Pressure at inlet entrance & $825.76 \mathrm{~Pa}$ \\
Inlet Mach number & 12.5 \\
Operating altitude & $32.5 \mathrm{~km}$ \\
Operating temperature & $229.58 \mathrm{~K}$ \\
\hline
\end{tabular}

The operating conditions for the analytical design are presented in Table 1. The design is performed under calorically perfect condition. An overall inlet temperature ratio of 3.4846, corresponding to the combustor inflow temperature of $800 \mathrm{~K}$, was set as the design parameter to limit the flow temperature sufficiently below the auto ignition temperature of hydrogen-air mixture. From the analytical results for twoshock model, the bow shock temperature ratio is found 2.03; the remaining of which is seen across the internal shock. During the transition from two-shock to three-shock model, this temperature ratio is divided between the bow shock and the external shock. 


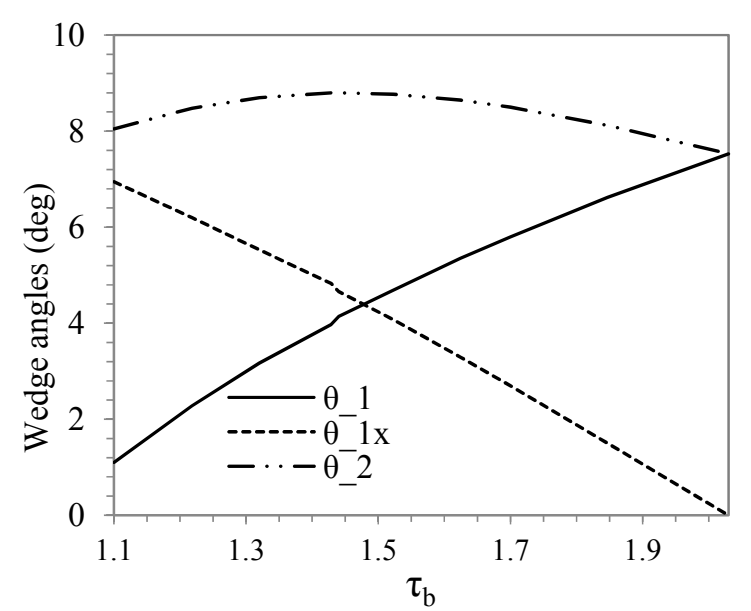

(a)

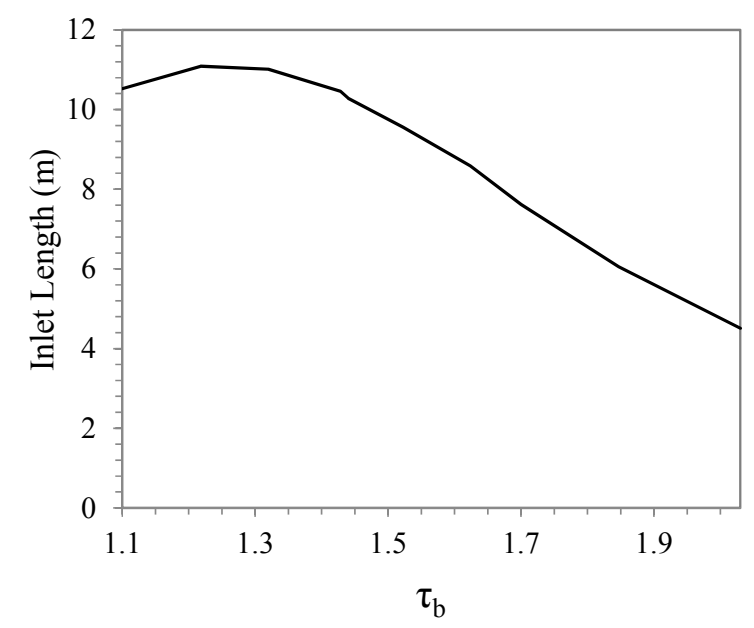

(c)

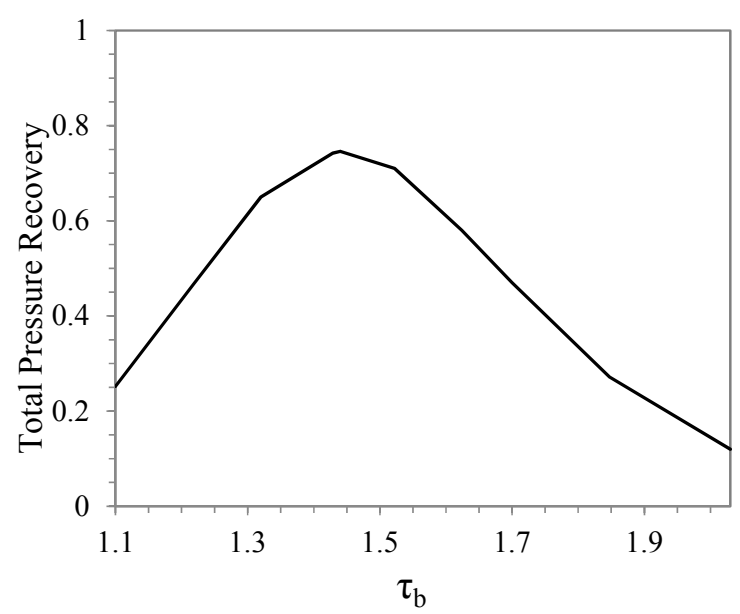

(b)

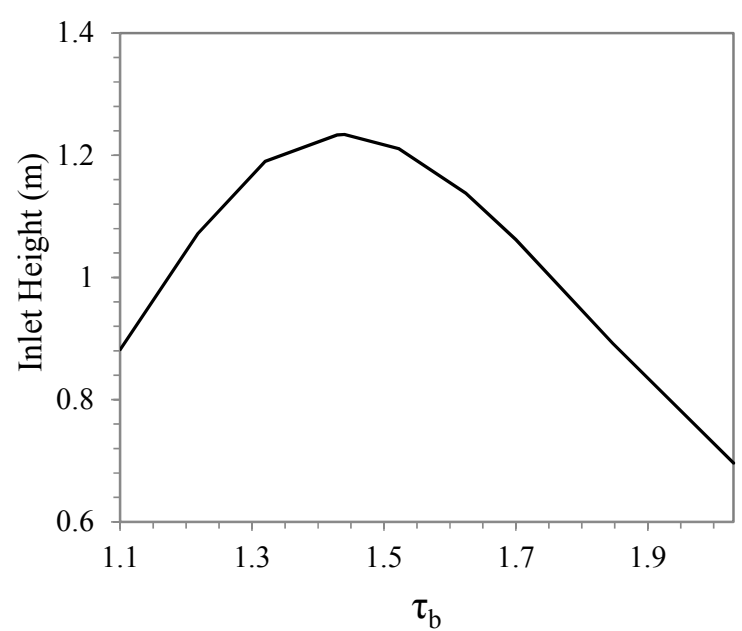

(d)

Figure 3. (a) Inlet Wedge Angles; (b) Analytically calculated Total Pressure Recovery at calorically perfect condition; (c) Inlet length variation along $\tau_{b}$; (d) Inlet height variation along $\tau_{b}$

The inlet wedge angles are plotted with respect to the bow shock temperature ratio as shown in Figure $3 a$. As the transition to three-shock occurs, $\theta_{1 x}$ increases corresponding to a decrease in bow shock temperature ratio. The change in the inlet size parameters with varying bow shock temperature ratios is shown in Figures $3 \mathrm{c}$ and figure $3 \mathrm{~d}$. The plots show that length and height of the inlet has a minimum value for the two-shock case. However, it comes with least total pressure recovery shown in Figure 3b. For an equal-strength bow and external shock system, $\tau_{b}=1.4246$. This three-shock system has the highest total pressure recovery but has a longer inlet length and height. Figure $3 c$ shows the inlet with $\tau_{b}=1.218$ has the longest length. Similarly, Figure $3 \mathrm{~d}$ shows inlet with $\tau_{\mathrm{b}}=1.44$ has the greatest height.

\section{Numerical Method}

The Shcramjet inlet flow field is computed using 2-D Euler equations. The mass, momentum and energy balance equations for inviscid, compressible and unsteady flow are written as: 


$$
\frac{\partial U}{\partial t}+\frac{\partial F}{\partial x}+\frac{\partial G}{\partial y}=0
$$

where,

$$
U=\left\{\begin{array}{c}
\rho \\
\rho u \\
\rho v \\
\rho\left(e+\frac{v^{2}}{2}\right)
\end{array}\right\}
$$$$
F=\left\{\begin{array}{c}
\rho u \\
\rho u^{2}+p \\
\rho u v \\
\rho u\left(e+\frac{v^{2}}{2}\right)+p u
\end{array}\right\}
$$$$
G=\left\{\begin{array}{c}
\rho v \\
\rho u v \\
\rho v^{2}+p \\
\rho v\left(e+\frac{v^{2}}{2}\right)+p v
\end{array}\right\}
$$

The above equations are solved along the ideal gas equation of state to describe the inlet flow field. The computation is performed in OpenFOAM CFD Toobox using the density based compressible rhoCentralFoam solver. The convective flux is calculated using central upwind scheme of Kurganov and Tadmore [22]. VanLeer TVD scheme is used for cell centered to face centered interpolation of primitive variables. Boundary condition at inlet and outlet are set as constant velocity inlet and extrapolated boundary, respectively. The inlet ramps and cowl are modelled as adiabatic walls. The constant pressure specific heat is calculated using 7 coefficients polynomial of JANAF thermodynamic table [23] in the form given in the below equation:

$$
C_{p}=R\left(\frac{a_{1}}{T^{2}}+\frac{a_{2}}{T}+a_{3}+a_{4} T+a_{5} T^{2}+a_{6} T^{3}+a_{7} T^{4}\right)
$$

\section{Results and Discussion}

A uniform 2D quad mesh with density $1784 \times 250$ is generated in the flow field for simulation, with the maximum Courant number of 0.4 and corresponding time step of $1.44 \times 10^{-08} \mathrm{~s}$. The computational domain of a two-shock case consists of a $0.4713 \mathrm{~m} \times 0.1047 \mathrm{~m}$ inlet body. Figure $4 \mathrm{a}$ shows the pressure flow field for the twoshock inlet model. The static pressure at the inlet exit is $18441 \mathrm{~Pa}$ and the average exit Mach number is 7.07. This design gives a total compression ratio of 22.33. The added advantage of shorter inlet length makes it a promising configuration in the Shcramjet forebody. However, despite having a shorter length, the two-shock inlet model suffers from a higher loss in total pressure recovery. Specifically at a high Mach number of 7.07 at exit, two-shock model gives a total pressure recovery of 0.641 shown in Figure 5a. The computational domain of three-shock inlet model with $\tau_{b}=1.4246$ consists of a $1.0411 \mathrm{~m} \times 0.1632 \mathrm{~m}$ flow field. Figure 4 shows the pressure contour of simulation of all the three-shock inlet models.

Considering a case with $\tau_{\mathrm{b}}=1.4246$, the static pressure at the inlet exit is $35371 \mathrm{~Pa}$ and the average exit Mach number is 6.6. This design gives a total compression ratio of 42.83 . Specifically at high Mach number of 6.6 at exit, this three-shock inlet model gives a total pressure recovery of 0.904 as shown in Figure 5a. 


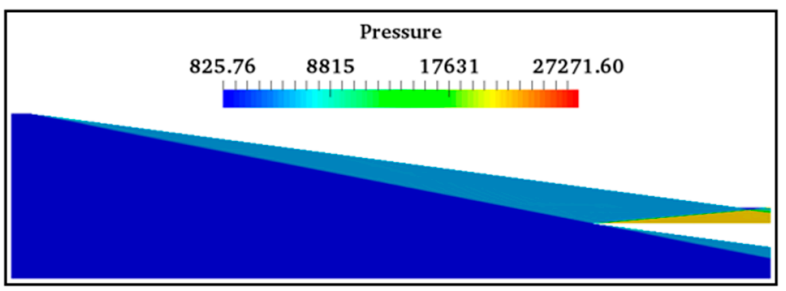

(a) $\tau_{b}=2.03$

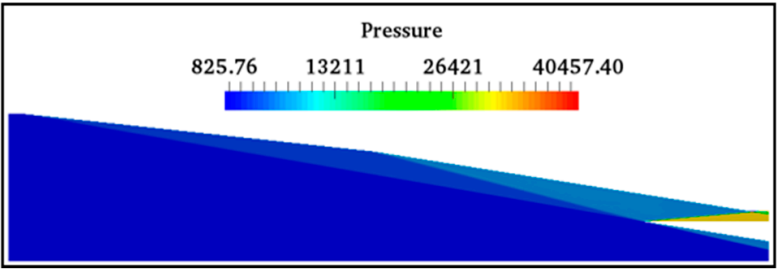

(c) $\tau_{b}=1.70$

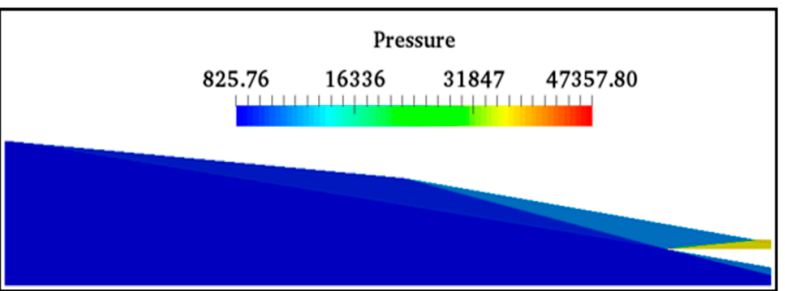

(e) $\tau_{b}=1.5225$

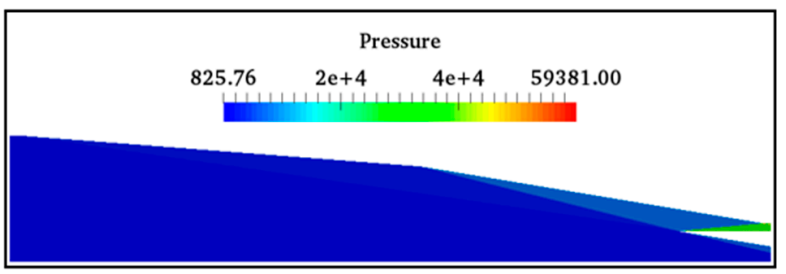

(g) $\tau_{b}=1.4246$

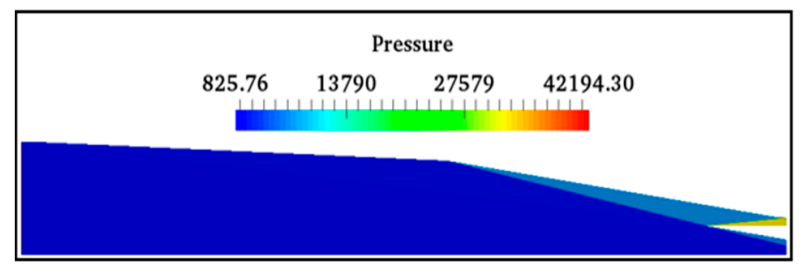

(i) $\tau_{b}=1.218$

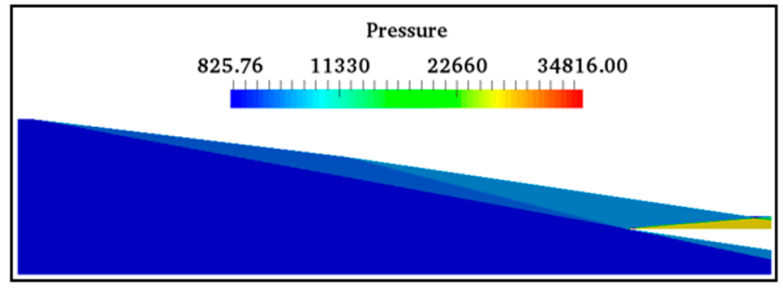

(b) $\tau_{\mathrm{b}}=1.847$

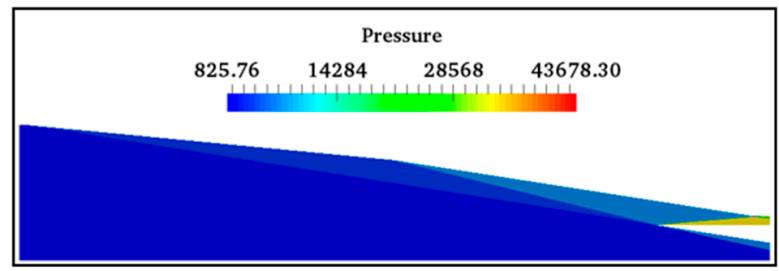

(d) $\tau_{b}=1.624$

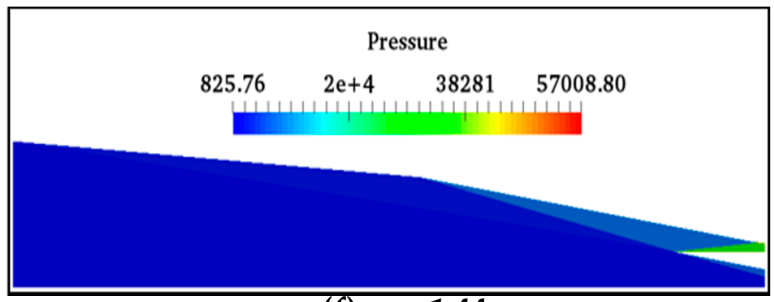

(f) $\tau_{\mathrm{b}}=1.44$

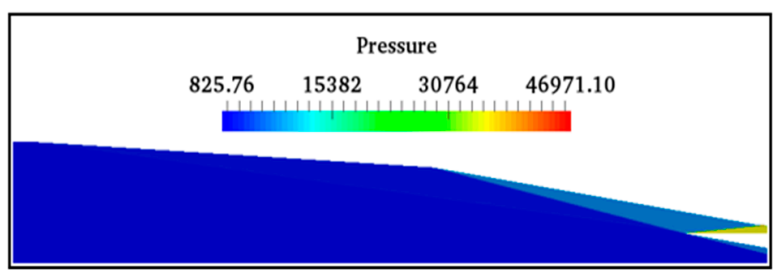

(h) $\tau_{b}=1.32$

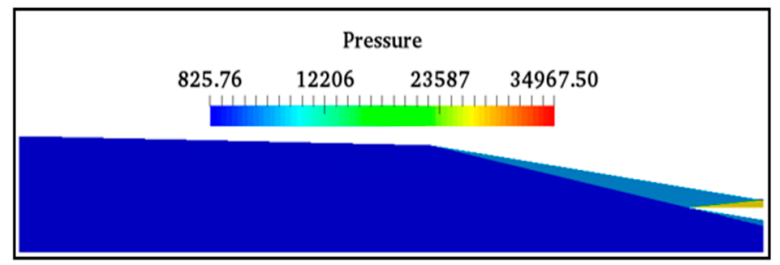

(j) $\tau_{b}=1.1$

Figure 4. Static Pressure (in Pa) Contours of numerically simulated geometries of ten different inlet cases 
The specific heat ratio plot in Figure $5 \mathrm{~b}$ shows a sudden jump in value of $\gamma$ as the flow passes across the OSWs formed inside the flow field due to significant change in flow temperature before and after OSWs. The value of $\gamma$ does not change significantly through the bow shock; hence, as seen in the Figure 6, the bow and external OSWs intersect near at the cowl lip. However, it changes aft of the external OSW, hence the internal OSW does not intersect at the end of the inlet wedge on the body. The three shock inlet case with $\tau_{b}=1.4246$ case has an added advantage of optimum flow temperature at outlet of approximately $790 \mathrm{~K}$ as shown in Figure $5 \mathrm{c}$ before entering into the combustor. The flow past the internal shock is normal to the inlet of combustor.

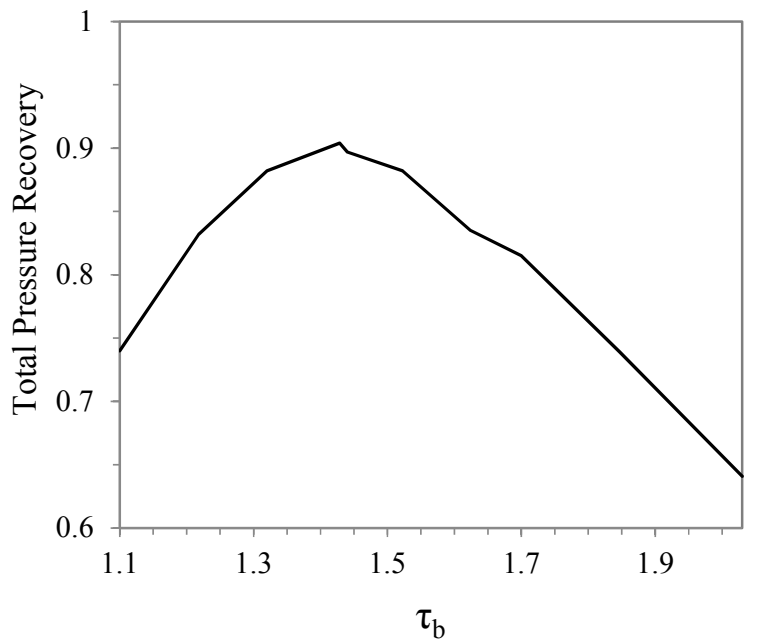

(a)

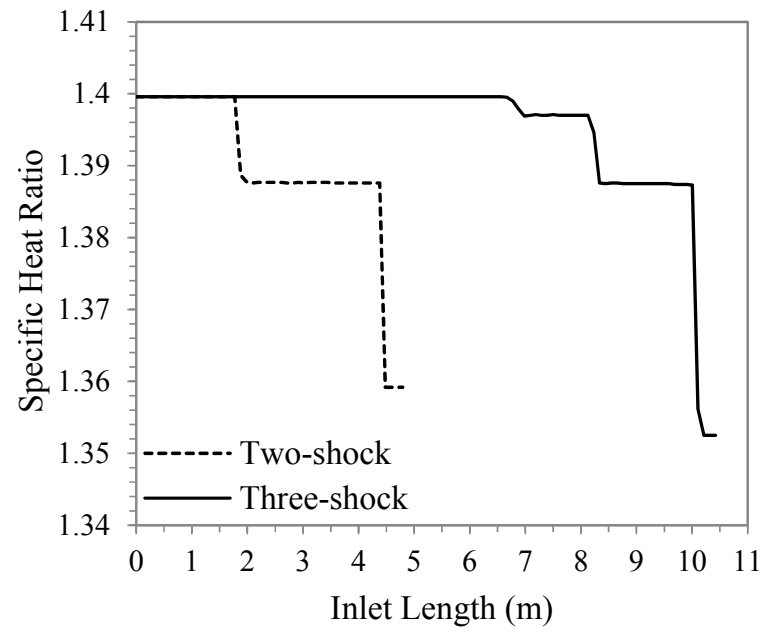

(b)

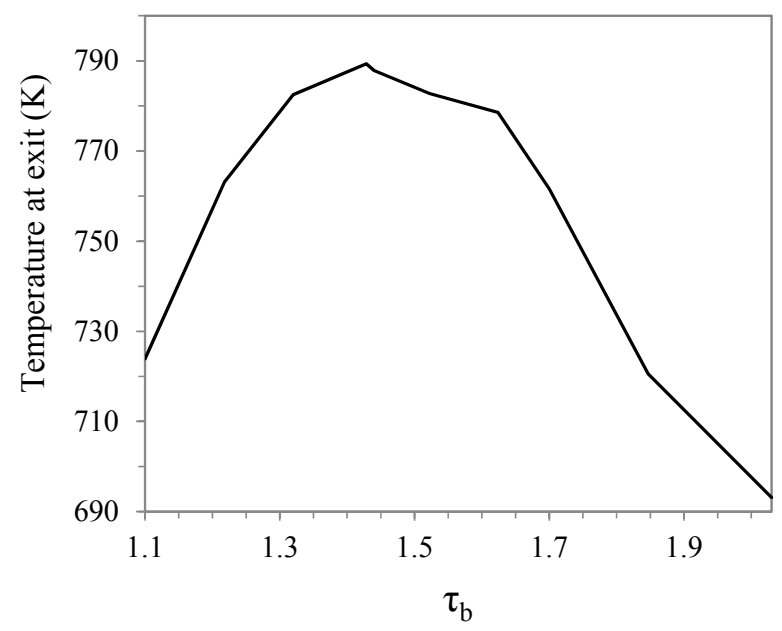

(c)

Figure 5. (a) Numerically Observed Total Pressure Recovery; (b) Specific Heat Ratio Variation along the inlet length; (c) Inlet Exit Temperature 
Figure 5a shows the numerically observed total pressure recovery of all the geometries analyzed. Despite increased length, three-shock inlet model is seen considerably more efficient in terms of total pressure recovery compared to two-shock system. Two-shock inlet model suffers from higher losses due to diffusion across two OSWs of greater strengths. On the contrary, the three-shock inlet model shows a method of diffusion across three OSWs of lower compression ratios that suffer from lower losses in terms of total pressure recovery. Though the viscous phenomenon has not been studied here, a longer inlet geometry will also suffer from larger frictional loss in the boundary layer due to shock-boundary layer interactions.

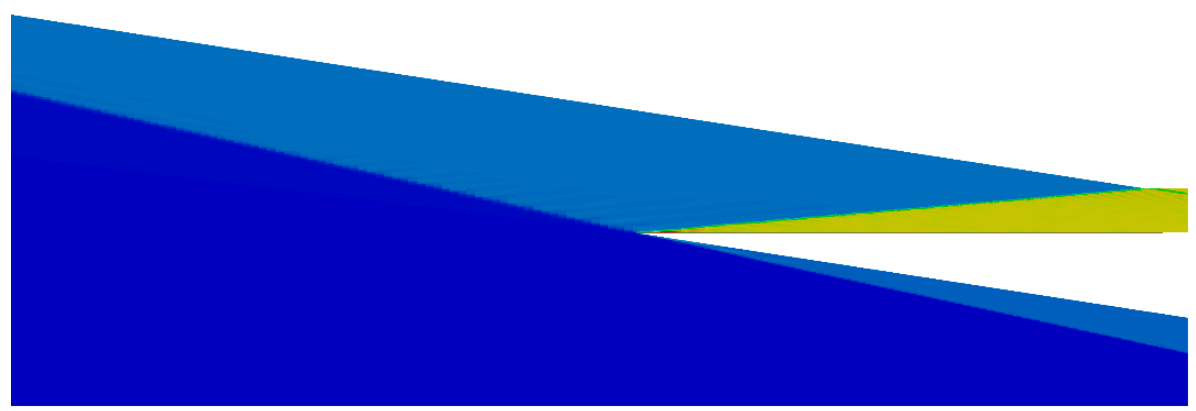

Figure 6. Numerically observed Shock-on-lip condition

\section{Conclusion}

The inlet of Shcramjet engine was designed at the flight conditions of Mach 12.5 and an altitude of 32.5 $\mathrm{km}$. The performed analysis of inlet flow field of a Shcramjet revealed that a strong tradeoff exists between total pressure recovery and the size of the inlet. While a two-shock model results in the smallest inlet size, the flow loss in terms of total pressure recovery is too high, hence requiring a three-shock inlet compression. The Shcramjet inlet geometry with a bow shock temperature ratio, approximately the square-root of the combined bow and external shock temperature ratios outperforms any other combination of OSWs in a Shcramjet inlet, provided the total pressure recovery is taken as the sole performance measure. The optimum distribution of strengths of the bow, internal and external shocks is determined in terms of temperature ratios to be 1.4246, 1.4246 and 1.71 for the three-shock inlet model based on maximum total pressure recovery. This case corresponds to the inlet length of $10.457 \mathrm{~m}$ and height of $1.233 \mathrm{~m}$. The method presented here could easily be adopted and extended to design the inlet of a Shcramjet engine at any arbitrary conditions.

Acknowledgement: This work was carried out under collaboration with Jiangsu Province Key State Laboratory of Aerospace Power System, College of Energy and Power Engineering, Nanjing University of Aeronautics and Astronautics, and supported by The National Natural Science Foundation of China (NSFC no. 51576098).

Conflict of Interests: The authors declare no conflict of interest.

\section{Nomenclature}

$\theta_{1} \quad=$ first wedge angle

$\theta_{1 \mathrm{x}} \quad=$ second wedge angle

$\theta_{2}=$ third wedge angle

$\beta_{1}=$ bow shock angle

$\beta_{1 \mathrm{x}}=$ external shock angle

$\beta_{2} \quad=$ internal shock angle 
$\mathrm{C}_{\mathrm{p}}=$ constant pressure specific heat, $\mathrm{Jkg}^{-1} \mathrm{~K}^{-1}$

$\gamma \quad=$ specific heat ratio

$\mathrm{R}=$ = specific gas constant for dry air, $\mathrm{Jkg}^{-1} \mathrm{~K}^{-1}$

$\mathrm{T}=$ temperature, $\mathrm{K}$

$\mathrm{Ma}=$ mach number

$\mathrm{P} \quad=$ pressure, $\mathrm{Pa}$

$\mathrm{U}=$ solution vector

$\mathrm{F}, \mathrm{G}=$ flux vectors

$\rho \quad=$ density, $\mathrm{kg} / \mathrm{m}^{3}$

$\mathrm{u}, \mathrm{v} \quad=$ velocity component in $\mathrm{x}$ and $\mathrm{y}$ directions

e $\quad=$ internal energy, $\mathrm{J}$

$\tau_{\mathrm{b}} \quad=$ bow shock temperature ratio

\section{References}

1. Sislian, J. P.; Atamanchuk, T. M. Aerodynamic and Propulsive Performance of Hypersonic Detonation Wave Ramjets. Proceedings of the $9^{\text {th }}$ International Symposium on Air Breathing Engines, AIAA, Washington, DC, 1989; pp. 1026-1035.

2. Bhattrai, S.; Tang, H. Numerical Study of Shcramjet Combustor Characteristic Control Techniques. Frontiers in Aerospace Engineering. 2013, 2, 3.

3. Dudebout, R.; Sislian, J. P.; Oppitz, R. Numerical Simulation of Hypersonic Shock-Induced Combustion Ramjets. Journal of Propulsion and Power. 1998, 14, 6, pp. 869-879.

4. Alexander, D. C.; Sislian, J. P. A Computational Study of the Propulsive Characteristics of a Shcramjet Engine. Journal of Propulsion and Power. 2008, 24, 1, pp. 34-44.

5. Bachchan, N.; Hillier, R. Hypersonic Inlet Flow Analysis at Off-Design Conditions, Proceedings of the 22nd Applied Aerodynamics Conference and Exhibit, Providence, Rhode Island, 2004.

6. Smart, M. K. Optimization of Two-Dimensional Scramjet Inlets. Journal of Aircraft 1999, 36, 2.

7. Chan, J. J.; Liangt, S. M. Numerical Investigation of Supersonic Mixed-Compression Inlet Using an Implicit Upwind Scheme. Journal of Propulsion 1990, 8, 1.

8. Anderson, W. E.; Wong, N. D. Experimental Investigation of a Large-Scale, Two-Dimensional, Mixed Compression Inlet System-Performance at Design Conditions. NASA TM X- 20161970.

9. Haberle, J.; Gulhan, A. Internal flowfield investigation of hypersonic inlet at Mach 6 with Bleed. Journal of Propulsion and Power 2007, 23, 5, pp. 1007-1017.

10. Haberle, J.; Gulhan, A. Experimental investigation of a two-dimensional and three dimensional scramjet inlet at Mach 7. Journal of Propulsion and Power 2008, 24, 5, pp. 1023-1034.

11. Das, S.; Prasad J. K. Starting characteristics of a rectangular supersonic air intake with cowl deflection. Aeronautical Journal 2010, 114, 3, pp. 177 -189.

12. Lind, C.A.; Lewis, M. J. The effect of shock/shock interactions on the design of hypersonic inlets, Proceedings of 26th Joint Propulsion Conference, AIAA, Orlando, FL, 1990, pp. 1990-2217.

13. Dunlap, R.; Brehm, R. L.; Nicholls, J. A. A Preliminary Study of the Application of Steady-State Detonation Combustion to a Reaction Engine. Journal of Jet Propulsion 1958, 28, 6, pp. 451-456.

14. Sargeant, W. H.; Gross, R. A. A Detonation Wave Hypersonic Ramjet. U.S. Air Force Office of Scientific Research 1959.

15. Menees, G. P.; Adelman, H. G.; Cambier, J. L.; Bowles, J.V. Wave Combustor for Trans Atmospheric Vehicles. Journal of Propulsion and Power 1992, 8, 3, pp. 709-713.

16. Ran, H.; Mavris, D. Preliminary Design of a 2D Supersonic Inlet to Maximize Total Pressure Recovery, AIAA 5th Aviation, Technology, Integration, and Operations Conference, Arlington, Virginia, 2005. 
17. Chan, J.; Sislian, J.; Alexander, D. Numerically Simulated Comparative Performance of a Scramjet and Shcramjet at Mach 11, 48th AIAA Aerospace Sciences Meeting Including the New Horizons Forum and Aerospace Exposition, Aerospace Sciences Meetings, 2010.

18. Heiser, W. H.; Pratt, D. T. Hypersonic Airbreathing Propulsion. AIAA Education Series, 1994.

19. Tarn, C. J.; Baurle, R. A. Inviscid CFD Analysis of Streamline Traced Hypersonic Inlets at Off-Design Conditions, 39th AIAA Aerospace Sciences Meeting and Exhibit, Reno, NV, 2001.

20. Molder, S.; Szpiro, J. Busemann Inlet for Hypersonic Speeds. Journal of Spacecraft and Rockets 1996, 3, pp. 1303-1304.

21. Billig, F.S.; Kothari, A. Streamline Tracing - A Technique for Designing Hypersonic Vehicles, 13th International Symposium on Airbreathing Engines, AIAA, September, 1997.

22. Kurganov, A.; Tadmor, E. New high-resolution central schemes for nonlinear conservation laws and convection-diffusion equations. Journal of Computational Physics. 2000, pp. 241-282.

23. Chase, M. W.; Davies, C. A.; Davies, J.R.; Fulrip, D. J.; McDonald, R.A.; Syverud, A.N. JANAF Thermochemical Tables. Journal of Physical and Chemical Reference Data. 1985.

(C) 2016 by the authors; licensee Preprints, Basel, Switzerland. This article is an open access article distributed under the terms and conditions of the Creative Commons by Attribution (CC-BY) license (http://creativecommons.org/licenses/by/4.0/). 